\title{
Networking
}

\section{Valuing primary care research: gold not alchemy}

Beverley Hancock and Sue Wilson Department of Primary Care and General Practice, University of Birmingham, Primary Care Clinical Sciences Building, Edgbaston, Birmingham, UK

In the UK, it was less than 10 years ago that the Department of Health acknowledged that research capacity was insufficient to deliver the National Health Service Research and Development (NHS R\&D) strategy (Department of Health, 1996). This recognition was rapidly followed by a series of reports concerned with research capacity. Most notable of these, for primary care, was the Mant Report (Department of Health, 1997). Among its recommendations, aimed at increasing the quantity and quality of primary care research, were the development of primary care research networks (PCRNs) to better coordinate R\&D activity and provide expert support. The report also proposed personal awards to support research careers at predoctoral, postdoctoral and career scientist levels. PCRNs developed (in numbers and activities) from the early 1990s, stimulated by factors including the development of research active general practices, supported by regional funding schemes, and availability of National R\&D Support Funding for research active primary care providers in the NHS (Culyer Report, Department of Health, 1994).

The Mant Report elicited a government commitment to double the amount spent annually on primary care $R \& D$ from $£ 25$ million to $£ 50$ million,

Address for correspondence: Beverley Hancock, Research and Training Facilitator, Research Support Facility, Department of Primary Care and General Practice, University of Birmingham, Primary Care Clinical Sciences Building, Edgbaston, Birmingham B15 2TT, UK. Email: b.hancock@bham.ac.uk

Paper submitted on behalf of the Steering Committee of the UK Federation of Primary Care Research Organisations:

Fenny Green, Caroline Gunnell, Denys Hancock, Beverley Hancock, Terri Harding, Rhian Hughes, Anthonia James, Mike Kirby, Louise Letley, Roy Marsh, Lucy McCloughan, Amy Scammell, Rose Streeton, Sue Wilson. still a modest amount when viewed in context. Primary care was previously disadvantaged in comparison with secondary care (Department of Health, 1996) and less than 5\% of R\&D support funding was spent on primary care (Campbell et al., 1999). However, NHS regional offices were sympathetic to the development of research capacity in primary care and approximately one fifth of their annual expenditure related to primary care (Campbell et al., 1999).

The need to support research in primary health care is not just a local concern. Networks of research practices have also been established in Canada, the US and the Netherlands (Beasley et al., 2004). In 2001, the International Federation of Primary Care Research Networks (http://www.ifpcrn.org) was launched in order to facilitate international collaboration in the development of research and research capacity.

The last decade has seemed like the beginning of a golden age for primary care R\&D. But is the gold beginning to lose its lustre?

Just as we are beginning to see the benefits of increased investment there are warning signs that resources might be diverted from investment in individuals and the networks that support them. And just as research in primary care by primary care is making real impacts, some have concerns that the focus may shift to primary care being used as a laboratory for industry and secondary carebased research studies.

The reports of the Bioscience Innovation and Growth Team (2003) and Academy of Medical Sciences (2003) argued the case for a mutually advantageous collaboration between the NHS and industry for patient benefit. This led to the formation of the UK Clinical Research Collaborative 
(UKCRC), a new clinical structure of subjectspecific research networks (going beyond primary care) to improve patient recruitment and facilitate the conduct of large-scale clinical trials and other research studies (Research for Patient Benefit Working Party, 2004). This report made no mention of PCRNs, yet these networks are an essential component of any future plans for multicentre trials that recruit patients from the general practice setting. National coordination of networks is a financially appealing model that has been introduced in Scotland; however, the benefits of this strategy have yet to be evaluated.

The UK Federation of Primary Care Research Organisations fully supports the aims of the UKCRC and welcomes its reassertion of the importance of building the research workforce, but few details of how this will be achieved are yet available. We await details of what support will be afforded to workforce development under any new infrastructure.

The role of PCRNs is the subject of serious debate. Core objectives for PCRNs were agreed with the Department of Health in 2000 and have been updated since. They include:

- facilitating the recruitment of practitioners and patients to multicentre trials and other externally funded research;

- facilitating collaboration on research between primary care practitioners and other health related agencies;

- disseminating information on potential research collaboration, training opportunities, funding and academic advice;

- encouraging practitioner participation in research activities;

- identifying and organizing research training for primary care practitioners.

A survey of UK Federation of Primary Care Research Organisation (UKFPCRO) members (UKFPCRN, 2004) found that while half were involved in trials recruitment, the bulk of their work was supporting individuals and organizations engaged in research. There are good reasons for continuing to support practitioner-based research. Among them is the fact that while many practitioners are content to limit their research contribution to collecting data on behalf of others, some are more likely to participate as research collaborators if they get something back. Another is the need to identify, encourage and support the next generation of researchers.

We urge caution that, in the rush to develop national research capacity, we do not 'throw the baby out with the bath water' and neglect the grass roots of capacity building, which have been so carefully nurtured by PCRNs. Capacity building initiatives focussed on primary care teams and individuals should not be scaled back before an evaluation of their contribution to the national research strategy has been completed.

Research studies have well-defined outcome measures to demonstrate the impact of interventions. Surprisingly, few research policy developments have specified outcome measures in advance or included a mechanism to evaluate the impact of the investment made. Published evaluations are rare but do exist such as the evaluation of networks in North Thames (Harvey et al., 2000), the Northern and Yorkshire NHS Regional Office's evaluation of the four networks in its region (2001) and the evaluation of research practices in the same region (Gray, 2000). Initiatives to build research capacity are particularly difficult to evaluate, partly because traditional outcome measures of publication and grant funding are insufficient for evaluating the progress of novice researchers and new research teams. But evaluations that address the objectives of these initiatives are essential.

Before shifting the emphasis too far away from individual capacity building and from recognizing networks as entities whose contribution goes beyond recruiting patients for multicentre trials, we believe that research policy makers should consider the following questions:

- Will there be sufficient researchers to meet the needs of primary care research in the future if opportunities to identify, train and support promising individuals are limited?

- How will promising individuals be able to apply for a personal award from a national funding body without early support?

- Has the shift from Research Funding for NHS Providers to Support for Science led to an increase or decrease in:

- the number of research active practices;

- the percentage of NHS funding on primary care research?

- Given the relatively small number of practices seeking accreditation from the Department 
of Health-funded Primary Care Research Team Assessment Scheme how can the number of practices that are willing to engage in research be estimated?

- Would primary care research capacity have continued to develop with the demise of regional support if it had not been for PCRNs?

- How do academic units, PCRNs and RM\&G consortia compare and contrast? How are their roles different and what is the unique contribution of each to research capacity building?

The 2001 research assessment exercise demonstrated that primary care has the ability to design and execute research of the highest quality (http:// www.hero.ac.uk).

Since 2001, the number of academic departments and the level of research activity have continued to grow. This increased research activity within academic primary care has been enabled by the collaboration of very large numbers of primary care practitioners; it is no longer uncommon for research studies to recruit from more than 100 practices. The development and maintenance of these networks of collaborating practices has been made possible by PCRNs.

Within networks, important research questions are being addressed that would not have arisen from an academic unit. PCRN staff are not alchemists we cannot transform all primary care practitioners into independent researchers but occasionally we find a gold nugget - a practitioner who becomes an active independent researcher.

\section{References}

Academy of Medical Sciences. 2003: Strengthening clinical research. London: The Academy of Medical Sciences.
Beasley, J.W., Dovey, S., Geffen, L.N., Gomez-Clavelina, F.J., Inim, V., Lam, C.C.K., Nugmanova, A., Qidwai, W., Pavlic, D.R. and van Weel, C. 2004: The contributions of family doctors to primary care research: an international perspective. Primary Health Care Research and Development 5, 307-16.

Bioscience Innovation and Growth Team. 2003: Bioscience 2015: improving national health; increasing national wealth. London: Department of Trade and Industry.

Campbell, S.M., Roland, M.O., Bentley, E., Dowell, J., Hassall, K., Pooley, J.E. and Price H. 1999: Research capacity in UK primary care. British Journal of General Practice 49, 967-70.

Department of Health. 1994: Supporting research and development in the NHS: report of the NHS R\&D taskforce. Culyer Report. London: HMSO.

Department of Health. 1996: Research capacity strategy for the Department of Health and the NHS. A first statement. London: HMSO.

Department of Health. 1997: $R \& D$ in primary care. National Working Group Report. Chaired by Professor David Mant. Leeds: NHSE.

Department of Health. 2000: Core objectives of primary care research networks. London: Department of Health.

Gray, S. 2000: Evaluation of the research practice scheme. Northern \& Yorkshire: NHSE.

Harvey, J., Fenton, E. and Sturt, J. 2000: Evaluation of primary care $R \& D$ networks in the North Thames region. Final report. Retrieved 1 October 2005 from, Warwick Business School, University of Warwick http://www.hero.ac.uk/rae/ Results

NHSE Northern and Yorkshire. 2001: Evaluation of the 4 primary care research networks in Northern and Yorkshire region. Leeds: NHSE Northern and Yorkshire.

Research for Patient Benefit Working Party. 2004: Research for Patient Benefit Working Party. Final report. Retrieved 2 December 2005 from, http://www.dh.gov.uk/ PolicyAndGuidance/ResearchAndDevelopment/fs/en

UK Federation of Primary Care Research Networks. 2004: Annual report, April 2003-March 2004. UK Federation of Primary Care Research Networks. 